\title{
El sentido de lo \\ comunitario. El caso de \\ la Fundación Procrear
}

Primer semestre de $2020 \cdot$ pp. 199-212

Segunda época

N. $^{0}$
The Sense of

Community.

The Case of

the Procrear

Foundation
O senso de

comunidade. 0

caso da Fundação

Procrear

\section{Claudia Milena Hernández Rodríguez*}

\section{Para citar este artículo}

Hernández, C. (2020). El sentido de lo comunitario. El caso de la Fundación Procrear. Folios, 51, 199-212. doi: 10.17227/folios.51-9943

Artículo recibido $20 \cdot 11 \cdot 2018$

Artículo aprobado $25 \cdot 07 \cdot 2019$

* Docente Departamento de Ciencias Sociales, Universidad Pedagógica Nacional. Cundinamarca, Bogotá, Colombia.

Correo electrónico: cmhernandez@pedagogica.edu.co 


\title{
Resumen
}

Este artículo es producto de una investigación realizada en la Fundación Procrear, durante el año 2017 y 2018. En esta abordé un enfoque cualitativo que centró la obtención de datos en el método etnográfico, la entrevista y la revisión documental, fundamentalmente del centro de escucha El Parche, diálogos familiares y la escuela popular de niños, niñas y jóvenes. Estos son programas que realiza Procrear con población en condición de sufrimiento social: habitantes de calle, trabajadoras sexuales, trabajadores informales, inmigrantes venezolanos y niños que habitan uno de los barrios más marginados y estigmatizados de la ciudad capital. En este marco, el objetivo de este artículo es describir la construcción de comunidad que ha realizado la Fundación Procrear en el barrio Santa Fe. Para realizar esta descripción identifiqué dos categorías centrales: el territorio y lo emocional. Entiendo el barrio Santa Fe como un territorio, es decir una construc ción socio-física de las representaciones frente al espacio habitado, sus usos, problemas delimitaciones y transformaciones en medio de dinámicas históricas de poder y significados sociales (Harvey, 2005); mientras que la dimensión emocional se manifiesta en los proyectos comunitarios y los vínculos emocionales que se construyen entre la Fundación y la población beneficiaria. Fue así como entendí la construcción de comunidad de Procrear en el territorio, no como la agrupación de individuos cuyo único elemento de convergencia es el contexto espacial, sino como un conjunto de vínculos emocionales, sostenidos por la solidaridad social que es la apuesta y función social de las emociones de la Fundación.

\author{
Palabras clave \\ comunidad; territorio; vínculos emocionales; solidaridad social
}

\begin{abstract}
This article is the product of an investigation carried out in the Procrear Foundation, between 2017 and 2018. I addressed a qualitative approach and used ethnographic methods: participant observation, interview and documentary review. Most of the data was collected by the listening to El parche, family dialogues and a girls, boys and youngsters popular school. Those are programs created by Procrear, intended to reach affected and vulnerable population: street dwellers, sex workers, informal workers, Venezuelan immigrants and children who live in one of the most marginalized and stigmatized zones in Bogotá. To start this investigation, I identified two central dimensions: the territory and the emotional. The Santa Fe neighborhood is a territory, meaning, a socio-physical construction of the representations in relation to the inhabited space, its uses, problems, delimitations and transformations amid historical dynamics of power and social meanings (Harvey, 2005). The emotional dimension is manifested in community projects and the emotional bonds that are built between the Foundation and the beneficiary population. Thus, I understood the construction of the Procrear community in the territory, not only as the grouping of individuals whose only element of convergence is the spatial context, but as a set of emotional ties, sustained by the social solidarity that is the commitment and social function of the emotions of the Foundation.

\author{
Keywords \\ community; territory; emotional bonds; social solidarity
}

\section{Resumo}

Este artigo é o produto de uma investigação realizada na Fundação Procrear, durante os anos de 2017 e 2018 . Nesta utilizei uma abordagem qualitativa, focada na obtenção de dados no método etnográfico, na entrevista e na revisão documental, principalmente do centro auditivo El Parche, diálogos familiares e a escola popular de meninos, meninas e jovens. São programas realizados pelo Procrear com uma população em condição de sofrimento social: moradores de rua, profissionais do sexo, trabalhadores informais, imigrantes venezuelanos e crianças que vivem em um dos bairros mais marginalizados e estigmatizados da capital. Neste contexto, o objetivo deste artigo é descrever a construção da comunidade que a Fundação Procrear realizou no bairro de Santa Fe. Para fazer essa descrição, identifiquei duas categorias centrais: o território e o emocional. Entendo o bairro de Santa Fe como um território, isto é, uma construção sócio física das representações diante do espaço habitado, seus usos, problemas, delimitações e transformações em meio à dinâmica histórica de poder e significados sociais (Harvey, 2005); enquanto a dimensão emocional se manifesta em projetos comunitários e os laços emocionais que são construídos entre a Fundação e a população beneficiária. Foi assim que entendi a construção da comunidade Procrear no território, não como o agrupamento de indivíduos cujo único elemento d; c;nvergência ; o contexto espacial, mas como um conjunto de laços emocionais, sustentados pela solidariedade social que é a aposta e a função social das emoções da Fundação.

\section{Palavras-chave}

comunidade; território; vínculos emocionais; solidariedade social 


\section{Introducción}

Era un jueves, 25 de mayo. Llegué a la estación de Transmilenio Calle 22, allí me encontré con Alejandro, quién me esperaba para llevarme a la casa de Procrear. Eran cerca de las 10:00 a.m., las calles estaban llenas de movimiento, en esas tres cuadras que separan Transmilenio de la Fundación pude ver de "todo": trabajadoras sexuales —jóvenes y mayores-, habitantes de calle (la mayoría hombres), mujeres transgénero, algunos comerciantes puerta a puerta y transeúntes desapercibidos. No es fácil caminar por ahí sin sentir algo de inseguridad, pero también de indignación. Este territorio se encuentra tan cerca del centro histórico y del centro internacional, pero a la vez es una antítesis del poder que ellos representan.

Después de esas tres cuadras de reflexiones y sentires, de indignarme por esa imagen naturalizada para muchos, llegamos a Procrear. En la entrada estaba Laura, una mujer joven, que la Fundación rescató de las drogas y que ahora trabaja allí. Ella acompañaba a una manicurista quien arreglaba las uñas a trabajadoras sexuales que impacientes se acercaban. Al cruzar la puerta me sorprendí al ver tantos habitantes de calle (¿15?) sentados en un salón con música urbana y colores intensos, cantando y compartiendo entre ellos, a este espacio lo llaman "el parche". Al subir las escaleras me cruzo con varios niños que van de salida. Converso con el director y alterno la conversación con miradas que van y vienen por la inmensa ventana del tercer piso que permite ver todo el movimiento de la Calle 21. Es una fotografía de esa Bogotá a la que muchos temen y niegan, ese territorio al que muchos voltean la cara, que nadie quiere cruzar... (Diario de campo personal, 25 de mayo de 2018).

Desde la sociología, en los últimos cuarenta años el término comunidad y sus diferentes acepciones (comunidad educativa, comunidad emocional, comunidad económica) se han popularizado en las ciencias sociales y humanas. Este sobreuso del término ha generado diferentes interpretaciones, llegando en algunos casos a reducir comunidad a un conjunto de individuos. Desde la perspectiva que intento defender, siguiendo la línea de Torres (2013) para hablar de comunidad, en una organización social como es el caso, no es suficiente la afiliación a un grupo social o la localización espacial, se requiere de otros elementos como la identidad colectiva, los proyectos futuros, de vínculos emocionales y emociones compartidas, de historias compartidas, de prácticas y lenguajes entre otros. Tampoco quiero decir con esto que todas las comunidades deban incluir cada uno de estos elementos, pues de lo que se trata es entender los sentidos, apuestas y pilares desde los cuales una organización social construye comunidad.

El relato inicial recoge dos elementos que, desde mi mirada, son centrales para entender la construcción comunitaria en Procrear: primero, el territorio del barrio Santa Fe, en un sector de profunda marginalidad social; y segundo, la dimensión emocional de la organización. Esto es, los vínculos afectivos que construye y la solidaridad social que es la apuesta y función social de las emociones de la Fundación. Dicho esto, el presente artículo se pregunta ¿Cómo una organización social como la Fundación Procrear construye comunidad en el territorio del barrio Santa Fe, antes llamado zona de tolerancia? La tesis que intento defender señala que, en sus casi 20 años de existencia, la Fundación ha reducido el sufrimiento social de los habitantes del territorio, a partir de la solidaridad social y que se manifiesta en una serie de programas. Estos son respuesta a las injusticias, es decir, una matriz emocional compartida: indignación por las injusticias, esperanza de cambio, las políticas del cuidado, desnaturalización de la pobreza, y la solidaridad social, entre otros.

La estructura por seguir para la presentación de los resultados es: primero, presentaré el marco teórico y metodológico que sustenta la investigación; segundo, haré una historización del territorio de acción de Procrear, esto es el barrio Santa Fe; y tercero, analizaré la dimensión emocional en la construcción de comunidad, esto es: la función social y política (de las emociones) y vínculos que se tejen en la Fundación. 


\section{Aclaraciones teóricas y metodológicas}

Empezaré señalando que la noción de comunidad ha sido usada de manera diversa, lo que devela la polisemia del término y a ella se han asociado categorías como: lazo social, territorio, cuidado mutuo, vida en común, tribu, empatía, sistema comunal, entre otros. Las asociaciones reflejan la riqueza y potencia del término y "permite confirmar que, bajo el mismo significante, estamos frente a una variedad de significados diferentes y hasta divergentes" (Torres, 2003, p. 194).

El concepto de comunidad ha sido ampliamente desarrollado en la sociología, desde su origen como ciencia social en Weber y retomado durante la primera mitad del siglo pasado por la Escuela de Chicago, con el análisis de los procesos urbanos y barrios populares para reconocer sus referentes de unidad e identidad. Torres hace una distinción importante entre dos formas de comunidad, en sus palabras:

La comunidad como modo de vida que organiza y da sentido al conjunto de prácticas de una población (como en el caso de los indígenas), y la comunidad como vinculo o proyecto fundado en un conjunto de creencias, valores, actitudes y sentimientos compartidos que pueden estar presente en los procesos, prácticas y proyectos que no necesariamente son comunidades en el primer sentido (Torres, 2013, p. 204).

Esta investigación se inscribe en la segunda referencia, "como vínculo y sentido inmanente" desde la cual la comunidad no es un conjunto cerrado de individuos que comparten la cotidianidad, sino una forma de vida de sujetos singulares y autónomos, que participan voluntariamente de un compromiso mutuo, del que se hacen solidariamente responsables. Esta noción de comunidad puede ser empleada para el análisis de las organizaciones sociales, entendidas estas como comunidades "intencionales" en tanto que surgen por la decisión de un grupo con el propósito deliberado de reorganizar su convivencia de acuerdo con normas y valores idealmente elaborados (Calero, 1984, p. 14), a diferencia de otras como las comunidades de pueblos originarios.
Con respecto a la metodología, se inscribe en el paradigma histórico hermenéutico, en tanto su carácter ideográfico tiene por objetivo el estudio de fenómenos sociales particulares que deben ser interpretados en su especificidad y ser situados contextualmente, en este caso las organizaciones sociales entendidas como comunidades; su carácter compresivo también contempla elementos de flexibilidad metodológica y el reconocimiento del investigador como un sujeto social constructor de conocimiento. En consecuencia, el enfoque es cualitativo, sustentado en:

- El método etnográfico a partir de la técnica de observación participante con un total de doce (12) observaciones registradas en diarios de campo. ${ }^{1}$

- Entrevistas semiestructuradas a fin de comprender, en la voz de los actores, la narración sobre sus experiencias, percepciones, emociones, es decir, su subjetividad en conjunto. En total se realizaron cuatro (4) entrevistas con trabajadores ${ }^{2}$ de la Fundación y conversaciones informales con participantes de la Fundación.

- Análisis documental, específicamente de documentos institucionales.

En cuanto a la selección de la muestra para las entrevistas se tomó como criterio la pertenencia y antigüedad de los miembros de la Fundación Procrear y, la participación con respecto a la población beneficiaria de los programas.

Finalmente, el análisis del material de campo ha sido debidamente organizado en matrices de análisis y categorizada en un enfoque que triangula lo deductivo e inductivo. En el primero, algunas categorías se derivan del marco teórico y el modelo de análisis; mientras que en el segundo se enfoca en las categorías emergentes del trabajo de campo.

1 Para el trabajo de campo se contó con la participación de Kimberly Sánchez, Heydy Paola Veira, Tatiana Suárez, Gabriela Martínez y Andrea Jiménez.

2 Tres técnicas comunitarias, una con una profesional de campo y uno de los fundadores, y actual director. 


\section{Territorio: el barrio Santa Fe}

El Barrio Santa Fe pertenece a la localidad catorce de Mártires y está ubicado entre las calles 26 y 21 y desde la Avenida Caracas hasta la carrera 23; a pocos metros del centro internacional y a otros tantos del centro histórico de Bogotá. Fue declarado zona de tolerancia en el año 2001 y posteriormente reemplazado a Zona Especial de Servicios de Alto Impacto (ZESAI) por el decreto 187 de 2002, que establecía condiciones sanitarias para ejercer el trabajo sexual en la zona comprendida entre la calle 19 y la 24 y desde la Avenida Caracas hasta la carrera 17.

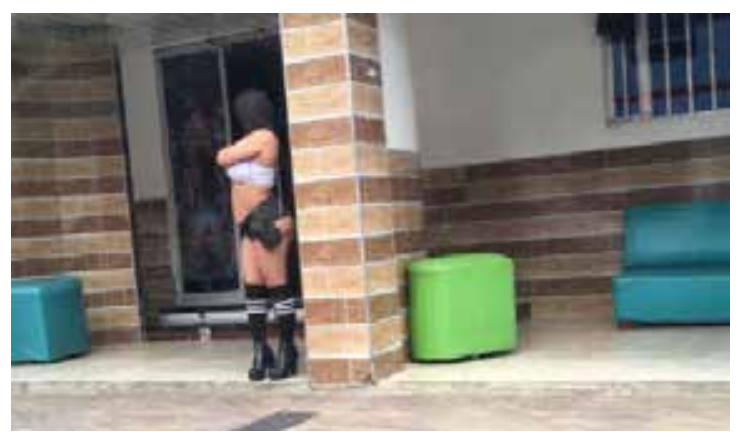

Foto 1: Zona Especial de Servicios de Alto Impacto

Fuente: Fotografía propia, tomada el 25 de agosto 2019 en la calle 23 entre carrera 15 y 16

"El Santa Fe", como es llamado en la jerga popular, es reflejo de la marginalidad social y económica, producto del modelo de desarrollo en el cual todo es susceptible de ser mercantilizado (incluida la vida y el cuerpo). Un modelo en el cual, para poder subsistir, muchas mujeres venden su cuerpo en condiciones denigrantes y exponen su vida a los vaivenes de la calle. El mismo sistema que avala y se favorece del narcotráfico y que da la espalda a sus víctimas: jóvenes, niños, ancianos, mujeres, afrodescendientes, muchos de los cuales lo pierden todo a causa de su adicción. El microtráfico de drogas ilícitas es el diario del barrio, siendo insuficiente la acción gubernamental para reducir y prevenir el consumo, el cual es tratado como un delito y no como una enfermedad, como un problema de salud pública. Para Piñeros,

En el sector constantemente se vulneran muchos derechos de los individuos y existe un nivel alto de marginación. Además, lo establecido por el
Decreto 188/ 02 que expidió la Alcaldía Mayor sobre las normas de la ZAI no se cumplen y se pasan por alto. Santa Fe se piensa como un lugar apartado de la ciudad y su complejidad ha llevado al deterioro de una parte de la historia de la misma. (Piñeros, 2010, p. 7).

Pero el barrio Santa Fe no siempre fue así, la fotografía del barrio hoy contrasta radicalmente con la de mediados del siglo pasado. En la década de 1940, cuando apenas iniciaba su fundación, el barrio era habitado por la élite capitalina, entre quienes se encontraban representantes de la clase política como Gustavo Rojas Pinilla, reconocidos poetas como León de Greiff (en foto 2) y uno que otro inmigrante que escapaba de la Segunda Guerra Mundial. El sector lucía una atmósfera intelectual y bohemia, caracterizada por el intercambio de ideas entre sus residentes, los cafés de tertulia, las artes y los teatros (un ejemplo es el Teatro Óskar, ubicado en la carrera 19 \# 22 D -17) y uno que otro lugar de lenocinio.

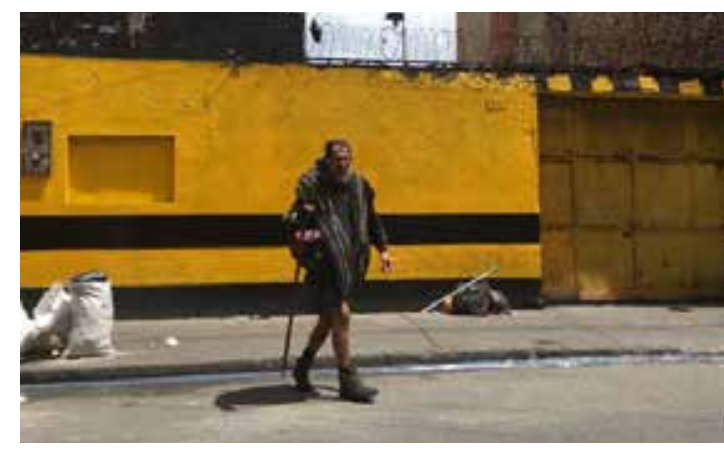

Foto 2: Antes casa de León de Greiff, hoy parqueadero público.

Fuente: Foto propia, tomada el 25 de agosto 2019 en la Carrera 16 No. $22-27$

Las fachadas de las casas eran muestra de la influencia arquitectónica alemana e inglesa, los techos a dos aguas adornaban el paisaje. Hacia mitad de siglo, muchos inmigrantes retornaron a sus países y Colombia comenzó a vivir una oleada migratoria interna como producto de la violencia bipartidista desatada en el campo por el poco desarrollo rural y las expectativas de progreso que representaba la capital con el proceso de industrialización. Fue así como antioqueños y caldenses, boyacenses y santandereanos, entre otros comenzaron a poblar 
la ciudad y barrios como el Santa Fe se convirtieron en centro de acopio de muchos de ellos.

Para la década del 60, el trabajo sexual del sector tomó más fuerza "de una forma discreta, aislada y sin producir ninguna clase de escándalos o molestias a los moradores del barrio." (Rueda, 1995, p. 25). Valga decir que esta actividad no era bien recibida por todos los vecinos quienes, con el favor de la iglesia católica, lucharon por acabarla, pero no fue así y por el contrario la actividad sexual desplazó la marca cultural que tenía el sector para convertirla a los ojos de los demás bogotanos como el centro de trabajo sexual en la ciudad. Para Natalia "es un barrio que permite visibilizar muchas realidades, el trabajo sexual desde niñas, mujeres trans, mujeres biológicas (...). Está cuadra de la veintiuna a la diecinueve son mujeres trans, pasando la Caracas hacia la 13, se ven mujeres mayores" (conversación personal, 4 de mayo 2017). Vinculado a ello estuvo el tráfico de drogas de toda índole y su consumo, y el trabajo sexual empezó a colindar con el delito de explotación sexual infantil.

Debido a la alta demanda habitacional y la poca disponibilidad del suelo, algunos propietarios adaptaron sus casas de familia como "apartamentos", inquilinatos y paga diario, favoreciendo el subarriendo. En la ciudad, según Cardeño:

[...] se fue incrementando vertiginosamente el número de habitantes; sin embargo, la superficie edificada no aumentaba con el mismo ritmo. El resultado fue un alta densificación de la población (...) que se evidenció en la subdivisión de las grandes viviendas coloniales (2007, p. 17).

En respuesta, los habitantes más acomodados decidieron mudarse del sector, ante el argumento de la "degradación del barrio". Además, a las marmolerías, las cafeterías y floristerías que se alimentan del Cementerio Central se fueron sumando otros negocios populares como fueron las salas de belleza, tiendas de ropa, restaurantes populares y sitios de rumba.

Fue así como el uso residencial de la Localidad fue trastocado por un uso mixto (comercial y residencial). La cercanía con las terminales de trasporte de buses y trenes (Estación de la Sabana) favoreció el crecimiento de los hoteles y alojamientos por horas, especialmente en el barrio La Favorita que colinda con el Santa Fe.

La historia de sectores como la calle del Bronx (entre calles 10y 9 sobre carrera $15 \mathrm{~A}$ y 15 bis) y la calle de Cinco Huecos (entre las calles 12B y 12 , sobre carreras 19A y 20) está relacionada con los usos desalojados de las plazas y los terminales de flotas que atraían actividades informales de todo tipo, como ventas callejeras, reparaciones, bodegas de reciclaje de botellas, papel y chatarra, y que fortalecieron sistemas de arriendo como el inquilinato (Cardeño, 2007, p. 95).

A finales de siglo pasado, el desalojo de la calle del cartucho y la construcción del Parque Tercer Milenio produjo una diáspora, sin antecedentes, de habitantes de calle y consumidores de drogas, muchos de los cuales encontraron lugar en el barrio. Estas problemáticas, el crecimiento de la pobreza y la desigualdad social que se agudizó con la implementación del neoliberalismo. Contribuyeron para que el Santa Fe y los barrios aledaños se convirtieran en un lugar de recepción de habitantes de calle, pero también de desplazados internos como la comunidad Embera y, más recientemente, venezolanos.

Es en este contexto que llega la Fundación Procrear al barrio Santa Fe, liderada por Susana Fergunson y un grupo de personas motivadas por reducir el sufrimiento social de esta población, luego de haber realizado dos exitosos proyectos en el Barrio Egipto entorno a la prevención de la drogadicción y la educación sexual cuerpos para la vida en el cual se atendieron en total a 100 jóvenes.

La Fundación llega al Santa Fe, se instala en un apartamento que contaba con dos oficinas, una sala de reuniones y un cuarto de sistemas. Allí se realizaban diferentes talleres, pero el que más gustaba a las participantes era el de computación.

[...] un apartamento pequeño, eran dos oficinas,

y la sala donde hacíamos reuniones y un cuarto de sistemas, pero hacíamos muchas cosas, muchísimos más talleres para las mujeres, uno de 
los que más nos gustaban eran las que clases de computación (conversación personal con Laura, 28 julio de 2016).

Es en ese momento que Procrear empieza a trabajar en la perspectiva de Modelo Epistemología de la Complejidad Ética y Comunitaria (ECO2) el cual en un juego de palabras resaltaba sus elementos centrales: Epistemología de la Complejidad (ECO), Ética y Comunitaria ECO. "ECO también hace referencia a la raíz griega que significa “Casa” y está en la etimología de Ecumenismo y Ecología, aludiendo a los procesos de inclusión social que promueve el modelo" (Primera Semana Diplomado de Actualización ECO2 Presentación del Modelo ECO2). En palabras del director y uno de los fundadores:

No es solo dictar el taller, sino en una ruta de sistematización, de formación, del trabajo en red para hacer movilización social y trabajo comunitario. Lo segundo, es que el modelo definía que el sitio donde se aplicara ahí tenía que estar la organización, era en la sede de la organización. (...) hay que vivir con la comunidad ciertas situaciones ¿cierto? y no solo ir dos horitas a la semana. (conversación personal, 28 de julio de 2016).

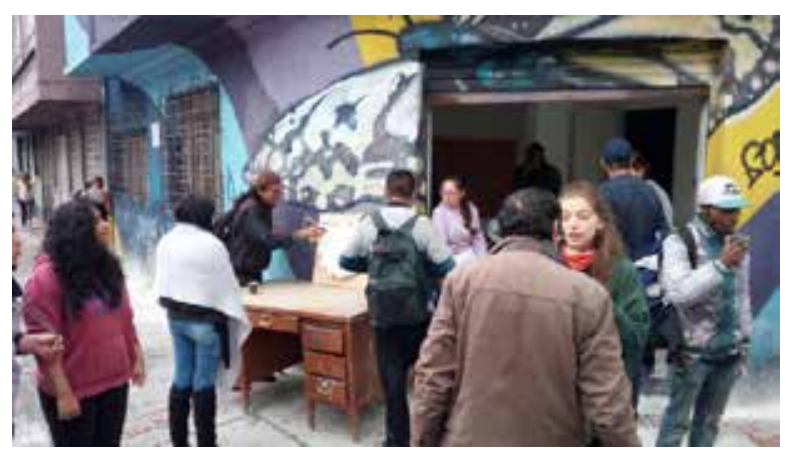

Foto 3: Entrada casa Procrear

Fuente: Fotografía propia, tomada el 10 de abril de 2018.

El barrio continúo la tendencia a la precarización y actualmente recibe familias humildes, trabajadores informales y formales, comerciantes de toda índole, desplazados internos y fronterizos, recicladores, población diversa dedicada al trabajo sexual y habitantes de calle. Según su director:
Aquí tenemos en el barrio personas víctimas de desplazamiento, personas afro, mujeres en ejercicio de prostitución, en los inquilinatos que existen en el sector hay personas de diferentes lugares del país que llegan aquí por diferentes motivos, hay población indígena (...) A los terminales si llega una familia o una persona desplazada lo primero que le dicen allá en el Santa Fe y allá en La Favorita hay lugares de dos mil y tres mil pesos, ¿qué se encuentra cuando la familia llega? un inquilinato donde en una pieza pueden estar durmiendo cuatro o cinco personas en una pieza (...) Pues hay diferentes situaciones que uno podría analizar de por qué una familia termina allí, familias que no tiene vínculos en la ciudad porque una familia que tiene vínculos en la ciudad puede coger para donde está su hijo. Llega gente por ejemplo de la Costa, del sector de Cali y Nariño y llegan buscando, buscando posibilidades (conversación personal, 28 julio de 2016).

La población en condición de calle sigue en aumento, pese a la existencia de programas gubernamentales y no gubernamentales para su atención. Según el último censo realizado por el Departamento Nacional de Estadística y la Secretaría de Integración Social, en Bogotá hay 9.538 personas en condición de calle, siendo Mártires la localidad con mayor presencia con 1.750 (Secretaría de Integración Social, 12 marzo 2018).

El imaginario del miedo ronda al barrio Santa Fe al ser visto como una zona de prostitución y venta de sustancias ilícitas, y su cercanía con lugares como el Bronx y Cinco huecos, lugares en los que confluyen toda serie de actividades ilegales. Además, y a propósito de la reciente violación y tortura de una niña de tres años en un jardín ilegal del barrio ${ }^{3}$, un informe de la Contraloría afirma que "la zona de tolerancia o alto impacto tuvo efectos en el aumento del microtráfico, explotación sexual de niños, niñas, adolescentes, mujeres y población tras y asesinatos" (Informe de la Contraloría, Murillo, 7 de mayo 2018).

3 El 4 de mayo del presente año, fue golpeada y violada una menor de tres años en el barrio Santa Fe. Ver noticia completa en: https:// www.semana.com/nacion/articulo/nina-violada-y-torturada-en-elcentro-de-bogota/ 565888 
Para Jimeno y Roldan "el miedo es la percepción de un peligro interno o externo, real, supuesto o anticipado. Es una señal de alarma que predispone a la huida, a la defensa o al ataque" (1994, p.192). Esta percepción es producto de las experiencias vividas, directas e indirectas y por tanto es también producto de los aprendizajes sociales recibidos por diferentes canales de socialización, es decir, el miedo también es aprendido. Esto se reafirma en el relato de Gabriela, monitoria de investigación, en el cual señala que "No quería llegar a la estación de la 22 temprano y sola, ya que me habían dicho que era un poquito peligrosa" (diario de campo de Gabriela, 10 de abril de 2018).

El miedo que puede sentirse frente a un objeto o sujeto está mediado por la manera en que es caracterizado, valorado y estereotipado. Estos procesos mediadores del miedo incluyen una carga ideológica y valorativa frente al otro, causal del miedo. $\mathrm{Al}$ estereotipar se definen los límites de lo posible, se encasilla y se reduce, con lo cual estereotipar es definir un ser reduciéndolo, es una forma de discriminar (Herzefeld, 1997). Esto es lo que sucede con los habitantes del barrio Santa $\mathrm{Fe}$, al ser individuos estigmatizados según Goffman (1962) se les lee bajo la "lógica de desviados socialmente" en donde prostitutas, drogadictos, delincuentes, criminales, homosexuales, entre otros, se les atribuye cierto tipo de rechazo colectivo (Citado por Murcia, Lugo, Rozo y Vega, 1998, p. 85).

\section{Dimensión emocional}

Hasta aquí he presentado las particularidades del barrio Santa Fe, que como dije, representa para muchos bogotanos un territorio del miedo, dada la precaria situación que allí se vive y la presencia notable de habitantes de calle. Este es el territorio en que se instala la Fundación Procrear, con el propósito de reducir el sufrimiento social de la población, y para esto desarrollan una serie de programas que son expresión de la solidaridad social de la Fundación.

Lo primero es señalar que el reconocimiento de las emociones en la construcción de la acción colectiva de las organizaciones sociales se antepone a aquellas posturas que la entienden bajo el cálculo "costo-beneficio". Tomando distancia de este enfoque, reconozco la centralidad de la dimensión emocional en las organizaciones sociales, que para el caso de Procrear se puede rastrear a través de los programas comunitarios que materializan la función social y política de las emociones; y los vínculos emocionales que se establecen en la Fundación.

\section{La función social de las emociones}

Para entender la importancia de las emociones en las organizaciones sociales retomo a Sarah Ahmed (2004) quien señala que las emociones no son estados psicológicos sino prácticas sociales y culturales; en consecuencia, lo central no es la naturaleza de las emociones sino la función social y política que cumplen, para qué sirven, qué hacen las emociones y cuál es su alcance.

Pero antes de estudiar para qué sirven las emociones, es preciso señalar cómo éstas configuran marcos de la acción colectiva. Para Delgado, estos esquemas son entendidos como "formas de comprender el entorno de problemáticas que implican la necesidad y deseo de actuar, como resultado de la negociación de significados y sentimientos preexistentes en una población" (2009, p. 40). Desde esta perspectiva se rompe con la lógica binaria que separa razón y emoción. Asimismo, el autor establece que los marcos de injusticia y la capacidad de agencia son (al igual que la identidad) elementos constitutivos de las organizaciones sociales.

Los marcos de injusticia "designan el inventario de orientaciones cognitivas y afectivas que un actor o movimiento social define y utiliza para comprender una adversidad como una situación de inequidad" (Delgado, 2009, p. 40). Para Procrear, la violencia y marginalidad social de los habitantes del barrio no son entendidas como una condición natural sino como el resultado de un modelo económico y de la guerra en que hemos vivido como sociedad, desnaturalizando así dicha condición. Esto se articula con sentimientos de indignación, rabia, dolor y derivan en la solidaridad social manifiesta 
en los programas comunitarios de la Fundación y mediante los cuales despliega su capacidad de agencia. Esto hace referencia a "la conciencia del actor social con respecto al sentido de éxito y eficacia de su acción para trasformar las condiciones ligadas a la problemática" (Delgado, 2009, p. 40).

Asimismo, Procrear hace énfasis en el ámbito político, entendiendo lo político no solo como poder del Estado, sino como la capacidad que tienen los sujetos y comunidades de incidir en sus propios asuntos y transformar sus contextos, en tanto que su apuesta es "mejorar la calidad de vida de individuos y comunidades" reduciendo "la vulnerabilidad y riesgos asociados con el consumo de sustancias psicoactivas y las enfermedades de transmisión sexual" (Celis, s. f., p. 7).

Las acciones y los programas de Procrear se enfocan en la función social y política de las emociones. Así, este tipo de organizaciones se convierten en "espacios de institucionalización de formas de solidaridad social presentes en la cotidianidad popular, son nudos del tejido local popular desde las cuales los pobladores se conforman como actores con capacidad de ser reconocidos por otros actores urbanos". (Torres, 2009, p. 70).

La solidaridad social pone en escena "criterios de valoración moral: el sujeto juzga la situación del otro como sufrimiento, innecesario, injusto, y halla en esta situación un riesgo que lo alerta frente a la posibilidad de llegar a padecerlo" (Rorty, 2001, p. 109). Esto se articula con unos procesos cognitivos de entender la marginalidad, aunque "la solidaridad tiene menos que ver con la racionalidad de los argumentos (...) y más con la sensibilidad de compartir con otros el sufrimiento y el rechazo a la crueldad" (Giraldo y Ruiz, 2014, p. 6). Siendo este el sustento que moviliza el quehacer de la Fundación y que solo es posible cuando se experimenta el dolor que viven ellos como si fuese dolor propio, es decir cuando hay empatía.

En Procrear la solidaridad está ligada a la empatía y esto es posible gracias al compartir las adversidades y dinámicas propias del territorio del Santa Fe. Tal como dice el director de Procrear "hay que vivir con la comunidad y no solo ir dos horitas a la semana" (conversación personal, 28 de julio de 2016). Además, "la solidaridad no se descubre, sino que se crea, por medio de la reflexión. Se crea incrementando nuestra sensibilidad a los detalles particulares del dolor y de la humillación de seres humanos distintos, desconocidos para nosotros" (Rorty, 2001, p. 18).

Sumado a esta acción de prevención y reducción del sufrimiento social, o mejor como condición para que esto sea posible, la coordinación de la Fundación se ubica en una postura de derechos y reconociéndose a sí mismos como defensores de los derechos humanos y gestores de paz. Además, dimensiona el lugar que ocupa la violencia social y la guerra en la reproducción de estas condiciones de consumo y marginalidad, en palabras del director: "Aquí hay un contexto caracterizado por la guerra y así lo ignore está tocando a todas las personas. Aquí tenemos muchos chicos que consumen y lo primero que nos hablan es del desplazamiento y del asesinato de sus papás" (conversación personal, 28 de julio 2018)

Esta apuesta política es también una apuesta pedagógica, en tanto que cada uno de los proyectos de Procrear buscan movilizar las subjetividades de los participantes, así como reconocerles su dignidad humana. En este sentido y dadas las condiciones de violencia de la que son objeto, buena parte del trabajo de Procrear radica en la prevención del consumo y la violencia en el trabajo desarrollado con los niños y jóvenes. Así como el acompañamiento a los cuidadores y padres de familia mediante estrategias pedagógicas y de emprendimiento, especialmente desde la contención sicológica, emocional y médica primaria. Veamos tres de sus principales programas:

El Parche está dirigido a habitantes de calles y tienen como objetivo ser un centro de escucha. "Nació hace casi 20 años, netamente en las calles, o sea itinerante, no había un espacio formal, sino que íbamos a la carrilera a hablar con ellos" (conversación personal con Laura, 18 de mayo de 2018). También se preparaban almuerzos y se vendía a muy bajo costo, apenas para que pudiera cubrirse 
el costo de los alimentos, "muchas veces cuando se acercaban habitantes de calle que no tenían como pagar, se les pedía que a cambio dejarán su tarro de pegante o un puñal, muchos lo hacían y con esto la Fundación se sentía doblemente agradecida" (conversación personal con Stefania, 18 de mayo de 2018). Luego comenzó el parche en la casa Procrear y se alternaba con el parche itinerante, es decir, llevar la Fundación a la calle, a la carrilera y lugares donde están ellos, llevarles un alimento, hablar con ellos, acompañarlos y contenerlos.

Actualmente, funciona 3 días a la semana: dos en la casa y uno en la calle. Las actividades varían, dependiendo de la intervención de los estudiantes de práctica de Medicina de la Universidad del Rosario, quienes asisten al espacio desde hace 15 años. A las 9:00 am se abren las puertas de la casa y se dispone de agua y jabón para lavar sus manos, "las personas aprovechan ese momento para lavar sus rostros, sus oídos y el cuello, el frío del agua y la calle les es ajeno a la necesidad de higiene" (diario de campo de Gabriela, 17 de abril 2018). Algunas veces se hace manicure y peluquería, también se intercambian favores, por ejemplo: a los chicos que saben peluquear se les presta la máquina y ayudan con esa tarea a cambio de ropa o mercado. En el transcurso de la sesión se les entrega un refrigerio, se ameniza el espacio y se realiza una actividad pedagógica.

El proyecto diálogos familiares comenzó en el año 2016, bajo la necesidad de integrar a sus procesos a los cuidadores de los niños y niñas que asisten a la Escuela Popular, para de esta manera lograr aumentar la incidencia en las familias del barrio. $\mathrm{Su}$ objetivo actual es "mejorar la calidad de vida y las realidades sociales de las familias del barrio desde un desarrollo incluyente e igualitario, a través de la generación de procesos de emprendimiento que permitan promover soluciones económicas sustentables haciendo énfasis en las mujeres". (Herrera y Galindo, 2018, p. 3). Una de las actividades más llamativas de este proyecto fue la feria gastronómica, cuyas ganancias fueron distribuidas de manera proporcional con sus ventas entre los participantes y de ahí nació el proyecto de emprendimiento iniciado en febrero de 2018.

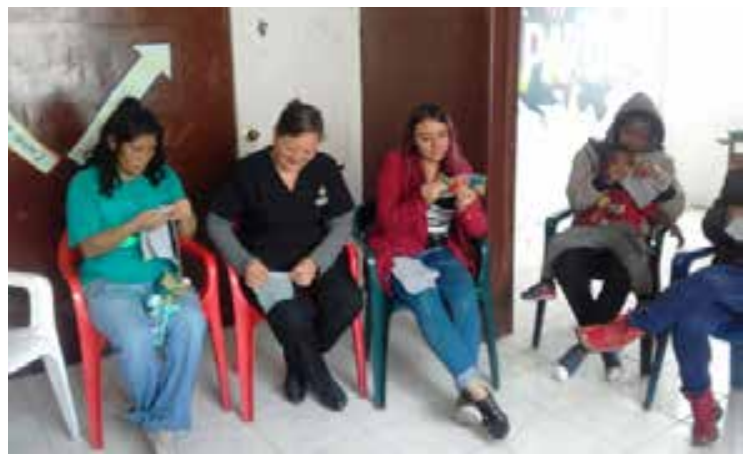

Foto 4: Diálogos familiares

Fuente: Fotografía propia, tomada en el taller de costura el 16 de marzo 2018

Mientras que la escuela popular es un proyecto financiado por la ONG Caritas Alemania, enfatiza en los niños y niñas del barrio, que "por medio de la metodología de Educación Popular se busca reducir los riesgos y daños posibles en sectores de alta vulnerabilidad" (Fundación Procrear, s.f.).

Este espacio está acompañado por estudiantes de la práctica de responsabilidad social de Uniminuto quienes hacen especialmente refuerzo escolar.

Pese a las diversas críticas que existen al asistencialismo, por alcance superficial y no estructurales Procrear considera vital garantizar a sus participantes un refrigerio o desayuno con el fin de suplir la necesidad de alimentación de estas personas, y brindar apoyo en atención básica de salud y en derechos sociales y reproductivos. Para esto cuenta con el apoyo de los estudiantes practicantes de Medicina y psicología de la Universidad del Rosario; también brinda la asesoría jurídica primaria cuando lo requieren y eventualmente se ofrece un mercado, comida o útiles escolares a las familias que participan de los programas.

\section{Vínculo emocional}

Hasta acá he señalado la importancia de las emociones en tanto proveedoras de acciones, es decir, la función social que cumplen la indignación, el dolor, la rabia, entre otras. Ahora abordaré lo que he llamado, la otra cara de la moneda de la dimensión emocional: los vínculos que se tejen entre los participantes, condición de toda comunidad intencional. 
Hablar de comunidad en la perspectiva que hemos señalado, implica reconocer un tipo de vínculo basado en lazos subjetivos fuertes, relaciones con compromiso emocional y moral. Esto es, desde la postura que intento defender no existe comunidad en las organizaciones sociales si no existe vínculo emocional entre los sujetos que la integran. Tal como señala Torres, "lo que hace que podamos llamar a un colectivo humano comunidad es la presencia de un sentido inmanente de un vínculo espiritual de una atmósfera sicológica que lleva a un sentimiento compartido de un nosotros" (Torres, 2003, p. 204). Ahora, hay un elemento central que permite entender cómo funcionan los afectos entre los profesionales y coordinadores de Procrear: el territorio. Muchos de los que hoy trabajan en la Fundación, se conocieron en el barrio o en la casa y desde ahí fueron formando amistades, compañerismos que son los que sostienen, cuando no hay recursos, la casa de puertas abiertas. Así lo dice Natalia, una de las técnicas comunitarias, "acá uno está por amor" (Conversación personal, 4 de mayo 2017).

Estos compañerismos entre los trabajadores de Procrear se basan en el afecto, amor por la labor que desempeñan y también por compartir unos marcos de interpretación y/o sistemas emocionales desde el cual leen y actúan en el mundo. El compromiso emocional se gesta entonces en relaciones propiciadas en campos emocionales o ambientes espaciales que reproducción redes de relaciones afectivas propias de una cultura afectiva (Reckwitz, 2012, p. 256). En estas se construyen rituales de interacción (Maffesoli, 2004) y auras estéticas (Collins, 2009). Los primeros permiten crear símbolos de pertenencia grupal que infunden energía emocional en sus participantes: mientras que el aura estética contiene elementos que remiten a la pulsión comunitaria. El vínculo emocional que se construye entre los participantes de la organización da cabida a la construcción de comunidades, como señala Laura "La Fundación significa muchas cosas, significa para mí: amistades, pasar mi tiempo muchas veces cuando estoy mal...encontrar afectos" (conversación personal, 28 julio 2016). Esto es ejemplo de lo que plantea Nisbet (1996) cuando dice que comunidad refiere a "todas las formas de relación caracterizadas por un alto grado de intimidad personal, profundidad emocional, compromiso moral, cohesión social y continuidad en el tiempo" (p. 71). Esta intimidad solo es posible donde existen vínculos de amistad y camaradería, que son fácilmente rastreables entre los sujetos participes de la Fundación. Así, los trabajadores no solo se vinculan a la Fundación porque compartan sus planteamientos sino que algo de su emocionalidad tiene lugar allí.

Asimismo, los habitantes de calle, trabajadoras sexuales que se benefician de los programas construyen vínculos con Procrear, que motivan especialmente su participación en los programas, y con esto quiero afirmar que no solo están allí por el refrigerio, la asesoría legal y el acompañamiento en la consecución de ciertos derechos. Están allí especialmente por la contención emocional y el lugar de acogida que representa Procrear, puesto que allí existe una experiencia de pertenencia, que adquiere un alto valor si se considera que la casa Procrear es uno de los pocos espacios de pertenencia de esta población, y sobre todo si se considera la ruptura familiar y social de los habitantes de calle, desplazados internos procedentes de diferentes regiones e inmigrantes venezolanos. Esta sensación de pertenecer a una colectividad implica:

\section{[...] la percepción de similitud con otros, el recono- cimiento de la interdependencia con los demás, la voluntad de mantener esa interdependencia dando o habiendo por otros lo que uno espera de ellos y el sentimiento de que uno es parte de una estructura más amplia, estable y fiable (Maya, 2003, p. 205).}

No fueron pocas veces en las que llegaron habitantes de calle, en horarios diferentes al habitual, a preguntar “¿hoy hay parche?, así como tampoco es casual que uno de los participantes de este programa nos haya dicho en una sesión "esto es como mi casa" y otro exprese que la casa es "un oasis". No es extraño, por ejemplo, que las sesiones cuenten con plena asistencia y que terminadas aún sigan ahí, sin quererse ir, cubiertos por un techo, en un espacio que ha sido adecuado para ellos. El parche es entonces un lugar físico, pero también emocional, desde su misma denominación se buscó que fuese 
cercano, amigable, familiar. Un lugar de parceros. Pero ¿qué pasa en el parche?

Cuando se abre $\mathrm{El}$ parche y los participantes cruzan la puerta, se separan inmediatamente de la hostilidad de la calle, encuentran en la casa, en el salón del primer piso un ambiente familiar, modesto pero dispuesto para compartir. Además de esto, los habitantes de calle están acompañados por un grupo de médicos en formación, se les ofrece el lavado de manos y cabeza, algunas veces se les habla de las enfermedades de trasmisión sexual y se les suministra preservativos, también hay sesiones de manicure y de corte de pelo.

El parche es un centro de escucha y efectivamente ellos están ahí hablando entre sí, con las sicólogas de Procrear, compartiendo una bebida caliente, se sientan en cómodos pufs o en sillas, escuchan música, cantan, ríen... el espacio está dispuesto para generar un aura estética (Maffesoli, 2004), una sintonía de bienestar. Para los participantes es dejar de lado "los guantes de pelea" que deben usar para sobrevivir a la hostilidad de la calle, pero también dejar por unas horas el consumo de diferentes sustancias. Heidy, monitora de investigación, lo relata así: "me quedé observando el salón y me llamó mucho la atención que hubiera mariposas pintadas, pues personalmente las considero como uno de los seres más hermosos de la naturaleza, llenas de poder para la transformación y libertad" (diario de campo de Heidy, 2 de marzo de 2018).

El lugar está ambientado de tal manera que propicia rituales de interacción, entendidos estos como un conjunto de procesos unidos en el que es fundamental el encuentro cara a cara y en el cual "los participantes desarrollan un foco de atención común y sus micro ritmos corporales y emocionales entran en consonancia recíproca" (Collins, 2009, p. 71). Cuando bailan y cantan se siente esta sintonía emocional que muy pocos espacios les permiten a los habitantes de calle.

Volviendo a la experiencia subjetiva de pertenencia, esta no solo sucede en el Parche, también se evidencia en la Escuela de Educación popular, tal y como señala Laura:
Estos niños son de los inquilinatos, allá viven en condiciones de hacinamiento, viven en un cuarto pequeño con sus papas, o a veces solo la mamá, y dos o tres hermanos más (...) Acá se les hacen actividades, se les da el refrigerio y de repente son re juiciosos, vienen todos los días a las nueve de la mañana y las doce cuando tienen que ir al colegio no se quieren ir, les gusta estar harto acá o porque no les gusta estar en la casa, o porque los papás se van todo el día a trabajar y no les gusta estar solos. (Paula, conversación informal, 28 de julio de 2016)

En la estrategia de diálogos familiares que acompañábamos los viernes, fue común ver que la planeación de cada sesión, volcada al emprendimiento, tuviera que ajustarse porque las mujeres que allí llegaban lo hacían con la intención especial de ir a conversar entre ellas. En una de las sesiones, entramos en lágrimas cuando una de ellas nos contó del asesinato de su hermano días antes, y en otra sesión nos vimos envueltos en una situación de angustia colectiva frente al arresto del hijo de Jakeline, quien fuese sorprendido hurtando en el trasporte público. Con esto quiero decir que el escenario de diálogos familiares más que un espacio de emprendimiento fue un espacio de contención emocional de las mujeres participantes, en el cual la empatía permitió ponerse en la experiencia de las otras y reconocer desde allí las emociones que se comparten en tanto madres y mujeres del barrio Santa Fe.

Así la casa de Procrear se convierte en un lugar de estar, que despierta un sentimiento de pertenencia, un punto de referencia y un lugar al cual se quiere volver, un lugar para compartir, para evitar la soledad que suele acompañar a estos niños, a los habitantes de calle y las trabajadoras sexuales o madres del barrio. Esto cobra vital importancia en tanto nos permite entender que las necesidades de esta población precarizada, marginada socialmente no son solo de orden económico o material, sino necesidades de protección (y cuidado) y necesidades de afecto (Max Neef, 1998); y es allí donde la Fundación cobra sentido como una casa, como un lugar de contención emocional, como una comunidad. 


\section{Conclusiones}

En este artículo he intentado presentar los modos en que la dimensión emocional y el territorio confluyen en la construcción comunitaria de Procrear. La dimensión emocional la analicé a partir dos ejes: la función social (de las emociones) manifiesta en sus programas el parche, diálogos familiares y la escuela popular; y los vínculos que se construyen entre la Fundación y la población beneficiaria.

Fue así como entendí la construcción de comunidad de Procrear como un conjunto vínculos emocionales, sostenidos por la solidaridad social que es la apuesta y función social de las emociones de la Fundación en un territorio tan complejo y marginal como el Santa Fe. Este es un territorio de miedo e inseguridad en el imaginario social, que genera rechazo entre los bogotanos, dado que allí conviven habitantes de calle, trabajadoras sexuales, traficantes de drogas, vendedores informales y formales, comerciantes de bares, desplazados internos y venezolanos. Si bien es importante en el estudio de las emociones, el repertorio emocional con el que se cuenta, es primordial en la comprensión de la articulación dimensión emocional y acción colectiva, dar cuenta de la función social de las emociones. Es decir, para qué sirven, qué hacemos con ellas y no exclusivamente que se siente y por qué. En este sentido, el recorrido etnográfico permitió entender la solidaridad como función social de las emociones, deriva de los marcos de respuesta a las injusticias que comparte la Fundación y desde los cuales desnaturaliza la marginalidad, la desigualdad social, la pobreza y las violencias múltiples. Asimismo, la casa de Procrear se convierte en un lugar de pertenencia para los beneficiarios de los programas, un lugar de contención emocional, como una comunidad.

\section{Referencias}

Ahmed, S. (2004). The cultural politics of emotion. London, Inglaterra: Routledge.

Murillo, O. (7 de mayo 2018). Jardines infantiles ilegales y otras tragedias del barrio Santa Fe. El Tiempo. Recuperado de https://www.eltiempo.com/bogota/ problemas-del-barrio-santa-fe-ponen-en-cuestion-zona-de-tolerancia-214640
Calero, D. (1984). Apuntes para una definición de lo comunitario. Comunidad, (46), 10-24.

Cardeño, A. (2007). Historia del desarrollo urbano del centro de Bogotá (Localidad de los Mártires). Bogotá, Colombia: Alcaldía mayor de Bogotá.

Celis, J. (s.f.). Presentación institucional. Bogotá, Colombia: Documento de trabajo inédito.

Collins, R. (2009). Cadenas de rituales de interacción. Barcelona, España: Anthropos.

Delgado, R. (2009). Acción colectiva y sujetos sociales. Análisis de los marcos de justificación ético-políticos de las organizaciones sociales de mujeres, jóvenes y trabajadores. Bogotá, Colombia: Editorial Universidad Javeriana.

Fundación Procrear (s.f.). Proyectos. Recuperado de: https://procrearfundacion.org/proyectos/

Giraldo, Y. y Ruiz, A. (2015). La solidaridad. El lenguaje de la sensibilidad moral. Revista Colombiana de Educación, (68), 311-334.

Harvey, D. (2005). El nuevo imperialismo: acumulación por desposesión. Buenos Aires, Argentina: CLACSO.

Herrera, E. y Galindo, J. (2018). Proyecto ComPrende y EmPrende. Diálogos Familiares. Documento de trabajo inédito.

Herzfeld, M. (1997). Culture intimacy social poetics in the nation-state. Nueva York, Estados Unidos \& Londres, Inglaterra: Routledge.

Jimeno, M. y Roldan, I. (1996). Las sombras arbitrarias, violencia y autoridad en Colombia. Bogotá, Colombia: Editorial Universidad Nacional.

Machín, J. (2010). Modelo ECO 2: redes sociales, complejidad y sufrimiento social. Revista hispana para el análisis de redes sociales, 18 (12), 305-325.

Maffesoli, M. (2004). El tiempo de las tribus. El ocaso del individualismo en las sociedades posmodernas. Buenos Aires, Argentina: Siglo XXI Editores.

Murcia, S., Lugo, N., Rozo, C. y Vega, L. (1998). Territorios del miedo en Santafé de Bogotá. Imaginarios de los ciudadanos. Bogotá, Colombia: Observatorio de Cultura Urbana-Tercer Mundo Editores.

Neef Max, M.(1998). Desarrollo a escala humana. Conceptos, aplicaciones y algunas reflexiones. Montevideo, Uruguay: Editorial Nordan-Comunidad.

Nisbet, R. (1996). La formación del pensamiento sociológico. Buenos Aires, Argentina: Amorrortu. 
Piñeros, D. (2010). Transformaciones del barrio Santa Fe en la ciudad de Bogotá (Tesis de grado). Universidad Javeriana. Bogotá, Colombia.

Rueda, I. (1995). Barrio Santafé 1930-1995 los hechos más sobresalientes. Bogotá.

Secretaría de Integración Social (12 de marzo de 2018). Según el censo Bogotá tiene 9.538 habitantes de calle. Bogotá, Colombia. Recuperado de http://www. integracionsocial.gov.co/index.php/noticias/98noticias-adultez/2358-segun-el-censo-bogotatiene-9-538-habitantes-de-calle.

Torres, A. (1995). Educación y pedagogía en las experiencias organizativas populares. La Piragua, Revista latinoamericana y caribeña de educación y política, (1), pp. 49-54.

Torres, A. (2007). Identidad y política de la acción colectiva. Bogotá, Colombia: Universidad Pedagógica Nacional
Torres, A. (2009). Acción colectiva y subjetividad. Un balance desde los estudios sociales. Revista Folios, (30), 51- 74 .

Torres, A. (2011). Sujetos, prácticas y sentidos de la participación local en Bogotá. Bogotá, Colombia: MGU-UPC.

Torres, A. (2013). El retorno a la comunidad. Problemas, debates y desafíos de vivir juntos. Bogotá : Arfo Editores.

Reckwitz, A. (2012). Affective spaces: a praxeological Outlook. Rethinking History, 16 (2), 241-258.

Rorty, R. (2001). Contingencia, ironía y solidaridad. Barcelona: Paidós. 